\title{
Fabrication of WC-TiC-6\%Co Hard Metals by micro-powder injection moulding
}

\author{
Aimin Jiang ${ }^{a}$, Bo Wen ${ }^{a}$, Quan $\mathrm{Li}^{\mathrm{a}}$ \\ Chongqing Academy of Science \&Technology, China \\ a44290159@qq.com
}

\begin{abstract}
Keywords: Micro-powder injection moulding; tungsten cemented carbides; carbon content; mechanical property.
\end{abstract}

\begin{abstract}
Micro-powder injection moulding (MIM) is the fastest growing technology within the powder metallurgy area. The reason for this growth is that it is an efficient production method. In this work, the fabrication of WC-TiC-6\% was studied. The result showed that Solvent debinding + thermal debinding was efficient to dislodge binders with no influence on the carbon content of samples. It' $\mathrm{s}$ better to remove the binders and control the carbon content of greens at $450^{\circ} \mathrm{C}$ and hold for 1.5 hour; During the liquid phase sintering process, with the $2^{\circ} \mathrm{C} / \mathrm{min}$ rate to heat up to $1430^{\circ} \mathrm{C}$ and hole for $90 \mathrm{~min}$ obtained the alloy and exhibited transverse rupture strength, Vickers hardness, coercivity and density are $1754 \mathrm{MPa}, \mathrm{HRA} 92.5,14.43 \mathrm{~g} \bullet \mathrm{cm}-3$. No carbon interspersion and $\eta$ phase appeared.
\end{abstract}

\section{Introduction}

WC-Co cemented carbides have been widely used as machining, cutting, mining and drilling tools, as well as wear parts and chip-less forming tools, due to their unique combination of extremely high hardness, high toughness, excellent wear resistance, and moderate modulus of elasticity ${ }^{[1-4]}$. However, they can only be made by a powder metallurgical process. As a result of the powder metallurgy traditional process technology's limit, components can only be formed and therefore designed with two dimensions of flexibility, the third dimension being reserved for the pressing operation, has affected cemented carbides 's application .

Powder injection molding (PIM) is a kind of net-shape powder metallurgy forming process ${ }^{[5-9]}$. This forming process maintains its metallurgical capabilities while using the powder and fabrication advantages of injection moulding, such as precise dimensional control, complex, Corresponding, geometry and near net-shape capability. It is a highly economical process for mass production of parts that are difficult to form or machine by conventional methods.

In the PIM process, powder is kneaded with binder to form the feedstock. Feed stock is then injected into the mould cavity, creating the desired shape. In the next step, the binder is removed from the green part using a proper solvent and thermal debinding process. Finally, the debinded part is sintered to obtain its final desired physical and mechanical properties such as high density and strength.The micro-powder injection moulding (Micro-PIM) process has attained significant interest from micro systems manufacturing. The Micro-PIM technique can be used for the fabrication of different metal and ceramic powders. Most studies in this field have been focused on stainless steel, zirconia and alumina because of their extensive usage in various applications; however, there are few reports that describe the details and challenges of micro-PIM of WC-Co. The expected applications for this process are those that demand wear resistance and high hardness in micro-components, such as micro-drill tools, micro-gear wheel and dental burs.

The mechanical properties of cemented carbides are influenced by many factors, among which carbon control is the most important for the alloys made by the PIM process because a lot of organic compounds are used in the binder [10-12]. Therefore, the binder composition and its debinding behavior are very important for making cemented carbide components with satisfying properties by PIM. In this study, an improved waxbased binder was developed for powder injection molding of 
WC-TiC-Co cemented carbides. The propertie of the feedstock and the injection molding process were studied.

\section{Experimental}

Materials. The mixed WC-TiC- $6 \%$ Co composite powder was used as raw materials. The characteristics of the powders are listed in Table 1. Small quantity (1.0wt\%)of TaC powder and quantity $(0.5 \mathrm{wt} \%)$ of $\mathrm{NbC}$ powder were added to WC-TiC-6\%Co composite powder. The binder used in this study consisted of 74\% Paraffin Wax (PW), 19\% Polyethylene Vinyl Acetates (EVA), High Density polyethylene (HDPE) and 1\% Stearin Acid (SA). The characteristics of the powders are summarised in Table 2.

Table1 Main characteristics of $\mathrm{WC}, \mathrm{TaC}, \mathrm{NbC}$ and Co starting powders.

\begin{tabular}{ccccc}
\hline Powder & $\begin{array}{c}\text { FSSS } \\
\mu \mathrm{m}\end{array}$ & $\begin{array}{c}\text { Oxygen } \\
\text { wt. } \%\end{array}$ & $\begin{array}{c}\text { Free carbide } \\
\text { wt. } \%\end{array}$ & Manufacturer \\
\hline $\mathrm{WC}$ & 0.4 & 0.3 & 0.08 & Xiamen Golden Rget Special Alloy Co., Ltd, China \\
$\mathrm{Co}$ & 1.28 & 0.42 & - & Nanjing Hanrui Cobalt Co., Ltd, China \\
$\mathrm{TaC}$ & 0.95 & 0.128 & 0.08 & wing high high-tech new materials Co., Ltd, China \\
$\mathrm{NbC}$ & 2.5 & 0.26 & 0.1 & wing high high-tech new materials Co., Ltd, China \\
\hline
\end{tabular}

Table 2 The characteristics of the binder's components

\begin{tabular}{ccccc}
\hline Binder & $\begin{array}{c}\text { Chemical } \\
\text { formula(wt.\%) } \\
\mathrm{C}_{\mathrm{n}} \mathrm{H}_{2 \mathrm{n}+2}\end{array}$ & $\begin{array}{c}\text { Melting } \\
\operatorname{point}\left({ }^{\circ} \mathrm{C}\right)\end{array}$ & $\begin{array}{c}\text { Density }(\mathrm{g} / \mathrm{c} \\
\mathrm{m} 3)\end{array}$ & $\begin{array}{c}\text { Decomposition } \\
\text { range }\left({ }^{\circ} \mathrm{C}\right)\end{array}$ \\
$\begin{array}{c}\text { Paraffin Wax (PW) } \\
\text { Polyethylene Vinyl } \\
\begin{array}{c}\text { Acetates (EVA) } \\
\text { High Density polyethylene } \\
\text { (HDPE) }\end{array}\end{array}$ & $\begin{array}{c}58 \\
\left(\mathrm{C}_{2} \mathrm{H}_{4}\right)_{\mathrm{x}} \cdot\left(\mathrm{C}_{4} \mathrm{H} 6 \mathrm{O}_{2}\right)_{\mathrm{y}}\end{array}$ & 80 & 0.9 & $164-315$ \\
$\left(\mathrm{C}_{2} \mathrm{H}_{4}\right)_{\mathrm{n}}$ & $140-150$ & 0.96 & $380-530$ \\
$\begin{array}{c}\text { Stearin Acid (SA) } \\
\mathrm{CH}_{3}\left[\mathrm{CH}_{2}\right] 1_{6} \mathrm{COO} \\
\mathrm{H}\end{array}$ & $64-70$ & 0.95 & $413-500$ \\
\hline
\end{tabular}

The binder components were mixed in a self-made mixing device,Feedstock was mixed below $110^{\circ} \mathrm{C}$ for $20 \mathrm{~min}$. Then the powder is added to the composed binder progressively up to the designed powder loading in a kneading machine at $50 \mathrm{rpm}$ for $2 \mathrm{~h}$. The mixing temperature was $150{ }^{\circ} \mathrm{C}$. The samples are molded with a SZ-28/250 injection molding machine at $140^{\circ} \mathrm{C}$. after-wards, mixing continued for $45 \mathrm{~min}$ at $150^{\circ} \mathrm{C}$, The injection pressure was $75 \mathrm{MPa}$ and the mold temperature was $30{ }^{\circ} \mathrm{C}$. The thermal debinding was carried out according to schedule 1 . ambient temperature $\stackrel{4^{\circ} \mathrm{C} / \mathrm{min}}{\longrightarrow} 70$

${ }^{\circ} \mathrm{C}$ (holding $\left.30 \mathrm{~min}\right) \stackrel{2^{\circ} \mathrm{C} / \mathrm{min}}{\longrightarrow} 190^{\circ} \mathrm{C}$ (holding $\left.90 \mathrm{~min}\right) \stackrel{1^{\circ} \mathrm{C} / \mathrm{min}}{\longrightarrow} 286^{\circ} \mathrm{C}$ (holding $\left.90 \mathrm{~min}\right) \stackrel{0.5^{\circ} \mathrm{C} / \mathrm{min}}{\longrightarrow} 393{ }^{\circ} \mathrm{C}$ (holding $80 \mathrm{~min}) \stackrel{2^{\circ} \mathrm{C} / \mathrm{min}}{\longrightarrow} 482^{\circ} \mathrm{C}$ (holding $\left.30 \mathrm{~min}\right) \rightarrow$ ambient temperature. The solvent debinding was performed in a heptane bath for 4 at $25^{\circ} \mathrm{C}$. Then thermal debinding was performed in a certain protection atmosphere according to schedule 2.ambient temperature $\stackrel{10^{\circ} \mathrm{C} / \mathrm{min}}{\longrightarrow} 286{ }^{\circ} \mathrm{C}$ (holding $20 \mathrm{~min}) \stackrel{10 / \mathrm{min}}{\longrightarrow} 482^{\circ} \mathrm{C}$ (holding $\left.30 \mathrm{~min}\right) \rightarrow$ ambient temperature. The mixed powders were then sintered using HIP-Sinter stove. the heating rate was $5^{\circ} \mathrm{C} / \mathrm{min}$, and a pressure of $15 \mathrm{MPa}$ was applied during sintering. The sintering temperature was set at $1430^{\circ} \mathrm{C}$ with holding time of 1.5 hour.

The density of samples was measure by the Archimedes principle with an analytical balance. The hardness was measured by Rockwell hardness. Transverse rupture strength was measured by three point bending test according to ASTM B528 standard. Meanwhile, the microstructure of cemented 
carbides were polished and corroded for micro structural analysis, which was carried out by scanning electron microscopy (JSM-6490LV) and optical microscope.

\section{Results and discussion}

\subsection{Debinding behavior}

Carbon content has an important influence on structure and properties of cemented carbide. The carbon content of trace fluctuations cause changes the phase composition of the alloy, thus affecting the performance of the alloy. The binder is made up of mixture of high polymer, carbon content of alloy will raising In the process of removing if binder are not totally removed. And then when alloy powder mixed with binder at high temperature in the container, the powder combine with oxygen from oxides which will reacts with carbon during degreasing and sintering.

Table 3 the effect of debinding method on carbon on carbon and oxygen content of the as debound specimens and as sintered specimens

\begin{tabular}{cccc}
\hline \multicolumn{2}{c}{ properties } & $\begin{array}{c}\text { Thermal } \\
\text { debinding }\end{array}$ & $\begin{array}{c}\text { Solvent debinding+Thermal } \\
\text { debinding }\end{array}$ \\
\hline $\begin{array}{c}\text { the as debound } \\
\text { specimens }\end{array}$ & $\mathrm{Ct} / \%$ & 5.69 & 5.41 \\
the as sintered & $0 / \%$ & 0.15 & 0.16 \\
specimens & $\begin{array}{c}\text { Cobalt } \\
\text { magnetic } \\
\text { phase }\end{array}$ & 5.79 & 5.38 \\
& $\mathrm{WC}+\gamma+\mathrm{C}$ & $\mathrm{WC}+\gamma$ \\
\hline
\end{tabular}

The table 3 showed the effect of debinding method on carbon on carbon and oxygen content of the as debound specimens and as sintered specimens. It was found that only thermal debinding could not remove binder completely, and the binder residue would increase the carbon content of the as debound specimens, and graphite phase was found in the micrograph of the as sintered specimens (Fig. 1). Two step debinding method (solvent debinding and subsequent thermal debinding) was also investigated. It was found that binder was almost removed completely after thermal debinding when specimens were hold at $482^{\circ} \mathrm{C}$ for 30 min according to schedule 2 , and no graphite phase or $\eta$ phase appeared. The method balanced the decarbonization effect of oxides and carburation effect of binder and achieved an ideal carbon control this is because the high temperature holding time is short enough to avoid decarburization, which indicates that the two step debinding method was endowed much flexibility to debinding atmosphere.

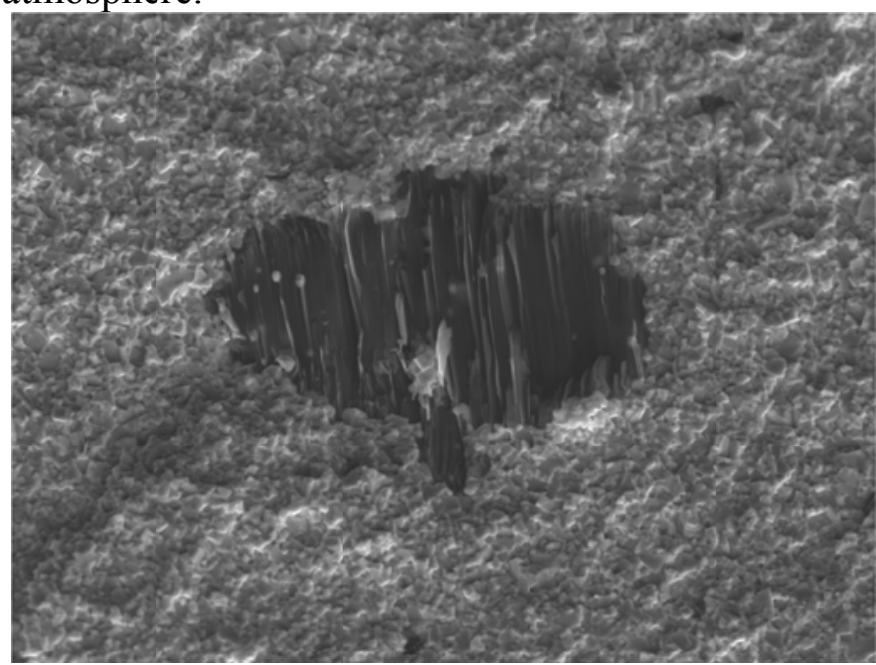

Fig 1. Microstructure of the WC-TiC-6\%Co tungsten cemented carbideformed by PIM (sintered at $1430{ }^{\circ} \mathrm{C}$ for $\left.1.5 \mathrm{~h}\right)$ 


\subsection{Microstructure and mechanical properties}

Physical properties of WC-TiC-6\%Co cemented carbide made by PIM were listed in Table 4. Fig. 2 shows the optical micrograph and Fig. 3 shows SEM of the crosssection. It was found that the density of PIM specimens is close to the theoretic value. The density and transverse rupture strength of products fabricated by PIM was slightly lower than fabricated by pressed, this is because injection moldling has low powder loadage, which limited the compactness of products. The void ratio is less than $0.02 \%$. The microstructure is homogeneous and free of the third phase. The transverse rupture strength and hardness of specimens sintered at 1430 for $1.5 \mathrm{~h}$ achieve1754 MPa and HRA92.5 respectively, which are similar to those of specimens made by conventional press and sinter technology.

Table 4 comparisons of tungsten cemented carbide made by PIM and press

\begin{tabular}{ccccccc}
\hline Process & Composition & TRS(Mpa) & Hardness(HRA) & Coercivity(KA/m) & Density & Void(\%) \\
\hline PIM & WC-TiC-6\%Co & 1754 & 92.5 & 19.9 & 14.43 & A02B00 \\
Press & WC-TiC-6\%Co & 1820 & 92 & 21 & 14.45 & A02B00 \\
PIM $^{[9]}$ & WC-8\%Co & 2500 & 90 & 8.95 & 14.72 & A02B00 \\
Press $^{[9]}$ & WC-8\%Co & 2500 & 89 & 8.95 & 14.72 & A02B00 \\
\hline
\end{tabular}

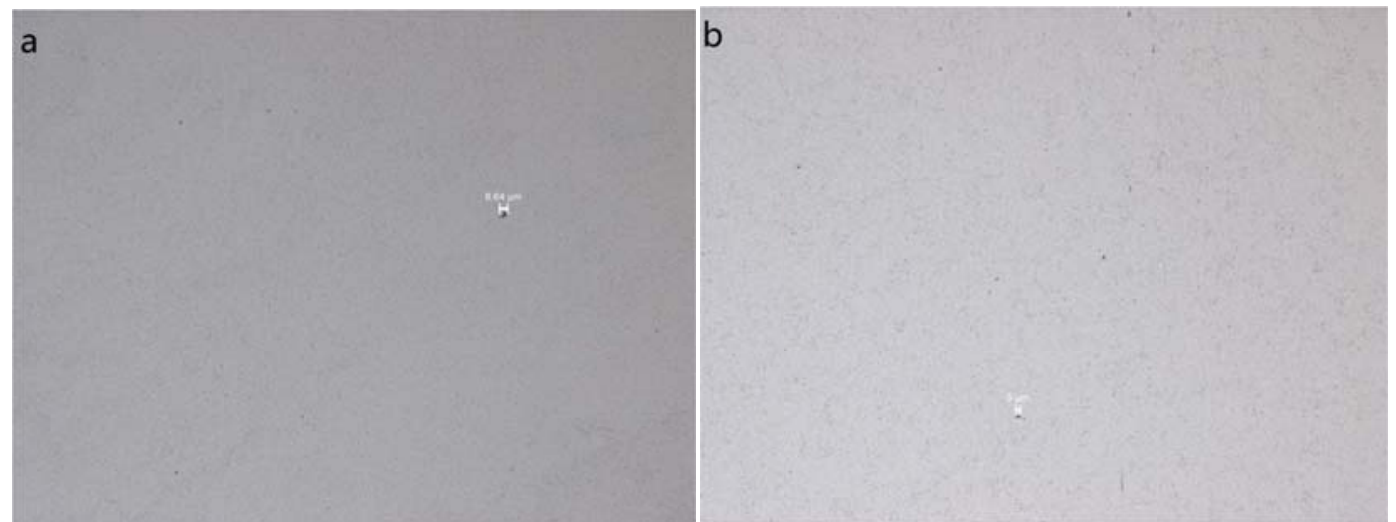

Fig 2 Optical micrograph of WC-TiC-6\%Co tungsten cemented (a) formed by PIM ;(b) formed by press

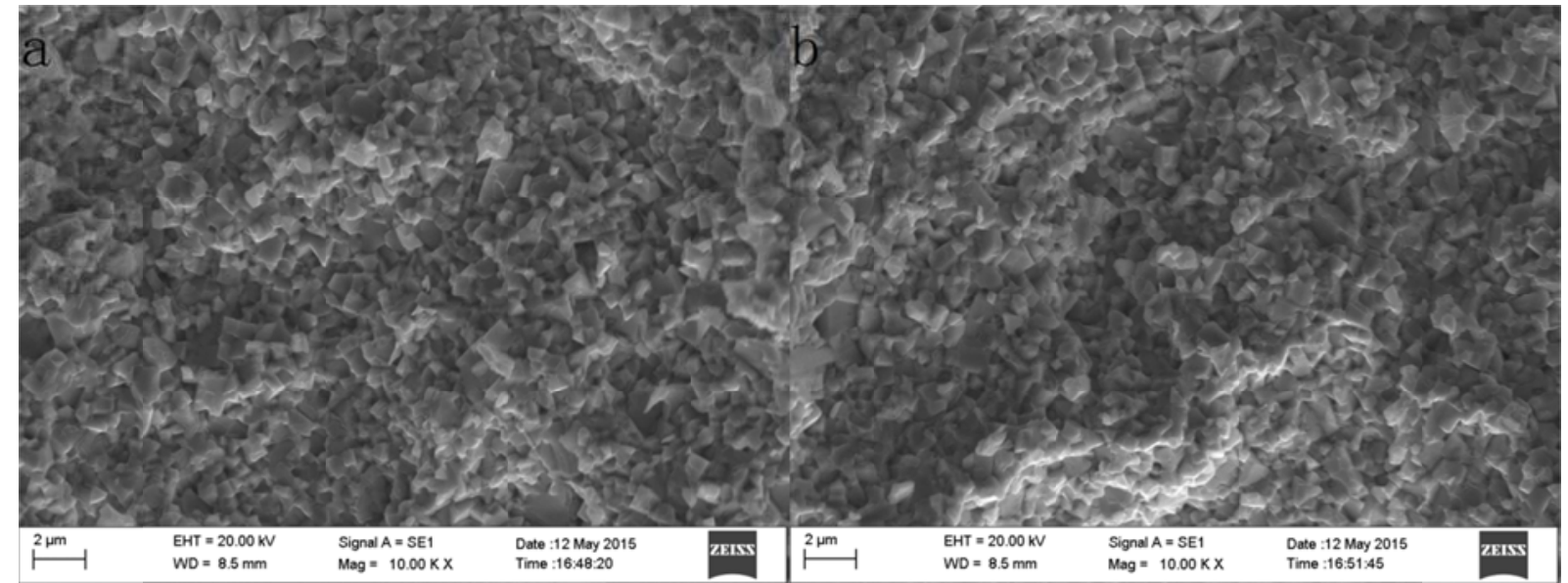

Fig 3 SEM of the cross-section of of WC-TiC-6\%Co tungsten cemented (a) formed by PIM ;(b) formed by press

\section{Conclusions}

The findings indicate that cemented tungsten carbide micro-components with dimensions of a few millimetres could besuccessfully fabricated using the micro-PIM process and a fine WC-TiC- $6 \% \mathrm{Co}$ powder as raw material together with PW,HDPE,EVA and SA as binder components. 
Only thermal debinding could not remove binder completely, leaving binder ash as graphite . Solvent debinding plus subsequent thermal debinding is more flexible and adjustable to debinding atmosphere, which would be beneficial to carbon control.

WC $-8 \%$ Co cemented carbide components were made by PIM. The transverse rupture strength, hardness, coercivity and density of the as sintered specimens made by an optimized PIM process were 1754MPa,HRA92.5, and $14.43 \mathrm{~g} \mathrm{~cm}^{-3}$ respectively.

\section{Acknowledgements}

The authors are grateful to Chongqing Academy of Science \&Technology for supplying of materials and testing of samples .the research work in this paper was supported by Natural Science Foundation Project of CQ CSTC(NO.CSTC2012jjA50030).

\section{References}

[1] M. Kawakami, O. Terada, K. Hayashi, J. Jpn. Soc. Powder Powder Metall. 2004;51:576

[2] Schubert WD, Lassner E. Brussels: ITIA Newslette r; June 2007.p. 2-10

[3] Tjong S.C. and Chen H. Mater. Sci. Eng R, 2004, 45: 1

[4] Wenbin Liu, Xiaoyan Song, Jiuxing Zhang, Guozhen Zhang, Xuemei Liu. Materials Chemistry and Physics, 2008, 109: 235-240

[5] L.E. McCandlish, B.H. Kear. Nanostructured Materials, 1992, 1(2):119-124

[6] X.M. Ma, J.I. Gang, J. Alloys and Compounds, 1996, 245:L30-L32

[7] Zongyin Zhang, Sverker Wahlberg, Mingsheng Wang, Mamoun Muhammed. Nanostructured Materials, 1999, 12:163-166

[8] L. Fu, L.H. Cao, Y.S. Fan. Scripta Materialia, 2001, 44:1061-1068

[9] Wenbin Liu, Xiaoyan Song, Jiuxing Zhang, Fuxing Yin. Nanostructured Materials, 2008, 458:36-371

[10] PETERSSON A, Agren J. Acta Materials, 2005, 53(6): 1665-1671

[11] MORTON C W, WILLS D J, STJERNBERG K. Int J Ref Met Mat, 2005, 23(4-6):287-293

[12] Arenas, F, de Arenas, I. B, Ochoa, J, Cho, S.-A. International Journal of Refractory Metals \& HardMaterials. 1999, 17: 91-97 